\title{
Dynamic Parameters Identification for the Feeding System of Commercial Numerical Control Machine
}

\author{
Chen Guangsheng* and Li Haolin
}

\author{
School of Mechanical Engineering, University of Shanghai for Science and Technology, Shanghai, China
}

\begin{abstract}
The precision of high-speed CNC (Computer Numerical Control) machine are greatly influenced by the dynamic characteristics of servo system. To establish the servo system model accurately, the internal signals of NC, e.g. motor current and rotate speed were adopt as the input or output signal for the system. The ARMA linear identification model was also established to identify the dynamic parameters of the mechanical parts in the servo system, including equivalent inertia, equivalent damping and so on. The friction Stribeck curve was obtained by necessary experiments. The nonlinear friction model was linearized by using higher-order Taylor expansion, and the five parameters of the Stribeck friction model were identified. To verify the effectiveness of the closed-loop identification, experiments are carried out on the feeding system of a commercial NC machine. Signals of servo motor current and rotating rate which are offered in many modern CNC machine tools are needed for the identification and experiments results show that the proposed method performs well with rapid convergence and accurate results and parameters of Stribeck model can be obtained accurately by identification. The method is suited for industrial condition and has its practicality.
\end{abstract}

Keywords: Computer numerical control machine, feeding system, parameters identification, dynamic parameters.

\section{INTRODUCTION}

High-speed and high-precision $\mathrm{CNC}$ machines are needed in modern manufacture. And the precision of highspeed NC machine is greatly influenced by the dynamic characteristics of servo system [1]. With regard to the highgrade commercial NC system in closed-loop control, the suitable control parameters of servo system are mainly determined by machine system parameters. However, improper control parameters can introduce higher following error for a servo system. Seriously, it can induce the oscillation of machine system, causing severe degradation in processing quality, even the damage of the machine. Therefore, the dynamic parameters of servo system should first be obtained to realize the modeling of servo system. Then high-speed machine in high-precision control can be achieved. Model of servo system is a closed-loop and comprised by three loops, with relatively more parameters that are difficult to be identified. The system identification of motor or worktable has been investigated by researchers $[2,3]$, but in which, experimental platforms of open-loop system are generally required to be established. Whereas, it is difficult to realize open-loop control restricted for commercial $\mathrm{CNC}$ system due to its closestructure, especially in the industrial field. Therefore, the identification of the commercial CNC system can be only performed in the condition of closed-loop.

In this study, the dynamic parameters such as inertia, damping of servo system, and the model parameters related to nonlinear friction for worktable are identified using system identification method.

*Address correspondence to this author at the School of Mechanical Engineering, University of Shanghai for Science and Technology, Shanghai, China; Tel: +86-021-55270938; Fax: +86-021-55270938;

Email: cgs-168@163.com

\section{MODELS FOR IDENTIFICATION}

\subsection{Model of Servo System}

Typical CNC machine feeding system is comprised by amplifier, servo motor, ball screw, screw nut, guide rail, worktable. Where, ball screw is driven by motors to exert the movement of screw nut. Thereby, the rotating motion of the motors is transferred to linear motion of working. Worktable is supported by sliding or rolling guide rail. And servo motor and rolling screw are directly connected by couplings.

To simplify the control model, without considering the elasticity of worktable, the mass and damping of all moving parts are all equivalent to the equivalent inertia and equivalent damping of motor shaft. The electro-mechanical coupling control system of the whole feeding system is show in (Fig. 1) [4]. And the symbols in (Fig. 1) are defined as follows: $\mathrm{u}$, the input signal of the controller, I, the current of the AC servo motor, $y_{m}$, the equivalent displacement of screw nut , 1 , screw lead, $K_{b s}$, the transferred coefficient of the nut displacement corresponding to motor rotation angle, $\Theta$ : the rotation angle of motor, $\grave{u}$, the rotation velocity of motor $\mathrm{K}_{\mathrm{pp}}$, the proportional gain of position loop , $\mathrm{K}_{\mathrm{vp}}$, the gain of velocity loop , $\mathrm{K}_{\mathrm{cp}}$, the gain of current loop , $\mathrm{K}_{\mathrm{t}}$, motor torque constant, $\mathrm{L}, \mathrm{R}$, equivalent inductance and equivalent resistance of motor respectively, $\mathrm{S}$, Laplace transform operator, Je ,equivalent inertia, $\mathrm{B}_{\mathrm{m}}$, equivalent damping.

\subsection{Stribeck Model Of Friction}

Stribeck model of worktable is an exponential model as well, proposed by Stribeck in 1902 [5,6]. Stribeck discovered that friction between two objects was associated with the membrane thickness of the lubricating oil, which varied with the change of the relative movement speed. Thus, friction is expressed by the function of the relative movement 
speed. And this is the known Stribeck curve, as shown in (Fig. 2). Seen from Stribeck curve, three kinds of friction is found with object's movement. When speed V was little, the static friction reduced to Coulomb friction with the increasing speed, and when speed V increased further, viscous friction showed a linear relation with speed. In stable-state movement, relations between friction and speed are described as follows

$$
F_{f}=F_{c} \operatorname{sgn}(v)+\sigma v+\left(F_{s}-F_{c}\right) \exp \left(-\left(\frac{v}{v_{s}}\right)^{\delta}\right) \operatorname{sgn}(v)
$$

Where, $F_{c}$ is coulomb friction force, $F_{s}$ is static friction force, $V_{s}$ is the critical Stribeck velocity, $\sigma$ is the viscous friction factor, $\delta$ is the Stribeck shape coefficient, usually 1 , $\mathrm{V}_{\mathrm{s}}, \mathrm{F}_{\mathrm{c}}, \sigma$ and $\mathrm{Fs}$ are usually obtained by parameters identification.

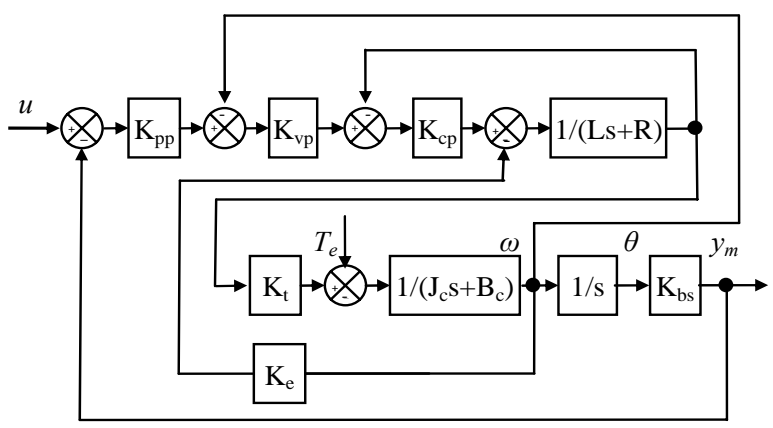

Fig. (1). Simplified electro-mechanical coupling control system of feeding system.

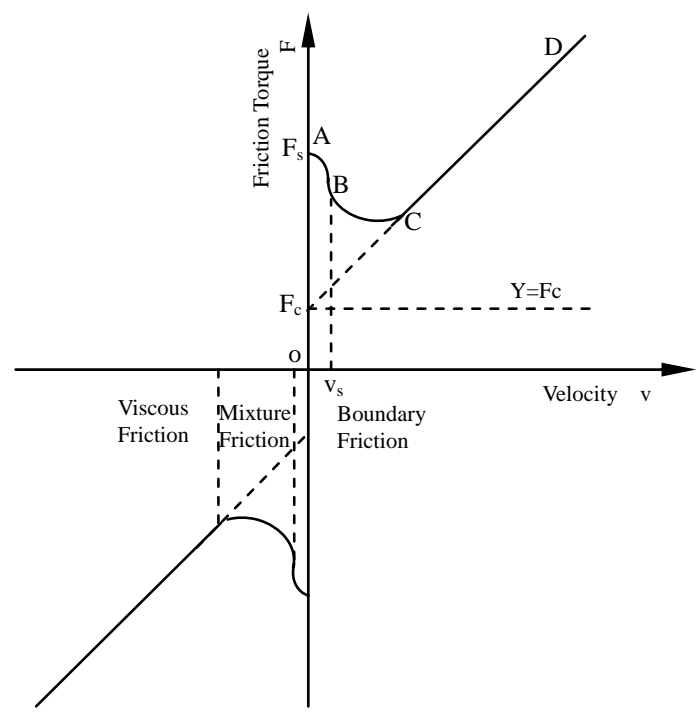

Fig. (2). Stribeck curve.

\section{PRINCIPLE OF IDENTIFICATION FOR DYNAMIC PARAMETER OF FEEDING SYSTEM}

\subsection{The Parameter Identification Using Least Squares Method Based on ARMA Model}

The least squares method is the most widely used one in system identification, since it is simple to be applied and can generate correct identification result. For a servo system following equation can be obtained $[3,7]$.

$$
K_{t} i=J_{e} \dot{\omega}+B_{e} \omega+T_{e}
$$

Eq. (2) can be written as:

$$
K_{t}\left(i-T_{e} / K_{t}\right)=J_{e} \dot{\omega}+B_{e} \omega
$$

After transferred by Laplace transform, it is:

$$
W(s)=\frac{b}{a} \times \frac{a}{s+a}\left[I(s)-T_{e}(s) / K_{t}\right]
$$

Where, $\mathrm{W}$ and I are the transferring forms of $\omega$ and i respectively, and suppose $a=B_{e} / J_{e}, b=K_{t} / J_{e} . \mathrm{T}_{\mathrm{s}}$ is taken as sampling period, discrete expression of Eq. (3) is rewritten as.

$$
\omega(k+1)=e^{-a T_{s}} \omega(k)+\frac{b}{a}\left(1-e^{-a T_{s}}\right)\left[i(k)-T_{e}(k) / K_{t}\right]
$$

Then $T_{e}(k) / K_{t}$ is equivalent to disturbing current, and it is derived from friction torque. Assume the disturbance current with $\omega$ is $d_{f}^{+}$, inverse disturbance current is $d_{f}$. Both of them can be considered as the functions of $\omega$, and then $T_{e}$ is described as follows [3].

$$
T_{e}(\omega(k))=P_{V}(\omega(k)) \cdot d_{f}^{+}+N_{V}(\omega(k)) \cdot d_{f}{ }^{-}
$$

In this equation, $P_{V}(\omega(k))$ and $N_{V}(\omega(k))$ are the functions illustrating the directions of $d_{f}{ }^{+}$and $d_{f}$ respectively, and they can be defined by the following equation:

$$
\begin{aligned}
& P_{V}(\omega(k))= \begin{cases}0 & \omega(k)<\Omega \\
1 & \omega(k) \geq \Omega\end{cases} \\
& N_{V}(\omega(k))= \begin{cases}0 & \omega(k)>-\Omega \\
-1 & \omega(k) \leq-\Omega\end{cases}
\end{aligned}
$$

Where, $\Omega$ is the threshold evaluating the direction of velocity, thus Eq. (3) is written as the following difference equations:

$$
\begin{aligned}
& \omega_{m}(k+1)=\left[\omega(k) i(k)-P_{V}(\omega(k))-N_{V}(\omega(k))\right] \\
& {\left[e^{-a T_{s}} b\left(1-e^{-a T_{s}}\right) / a b\left(1-e^{-a T_{s}}\right) d_{f}^{+} / a b\left(1-e^{-a T_{s}}\right) d_{f}^{-} / a\right]^{T}}
\end{aligned}
$$

Suppose

$$
\begin{aligned}
& \mathbf{Y}^{0}=\left[\begin{array}{llll}
\omega(2) & \omega(3) & \cdots & \omega(N)
\end{array}\right]^{T}, \\
& \boldsymbol{\theta}^{0}=\left[\begin{array}{llll}
e^{-a T_{s}} & b\left(1-e^{-a T_{s}}\right) / a & b\left(1-e^{-a T_{s}}\right) d_{f}^{+} / a & b\left(1-e^{-a T_{s}}\right) d_{f}^{-} / a
\end{array}\right]^{T}
\end{aligned}
$$

And

$$
\boldsymbol{\Phi}^{0}=\left[\begin{array}{cccc}
\omega(1) & i(1) & -P_{V}(\omega(1)) & -N_{V}(\omega(1)) \\
\omega(2) & i(2) & -P_{V}(\omega(2)) & -N_{V}(\omega(2)) \\
\cdots & \cdots & \cdots & \cdots \\
\omega(N-1) & i(N-1) & -P_{V}(\omega(N-1)) & -N_{V}(\omega(N-1))
\end{array}\right]
$$

In addition, in the formulas above, $\mathbf{Y}^{0}$ and $\boldsymbol{\Phi}^{0}$ are all known, only $\boldsymbol{\theta}^{\circ}$ remains unknown. Then the least squares method is employed to conduct identification, and the optimal estimation value of coefficient matrix is:

$$
\theta^{0}=\left(\left(\Phi^{0}\right)^{\mathrm{T}} \Phi^{0}\right)^{-1}\left(\Phi^{0}\right)^{\mathrm{T}} \mathbf{Y}^{0}
$$


And $a=-\ln \left(\boldsymbol{\theta}^{0}(1)\right) / T_{s}, \quad b=a \theta^{0}(2) /\left(1-e^{-a T_{s}}\right)$

$J_{e}$ and $J_{e}$ are obtained as

$J_{e}=K_{t} / b, B_{e}=a J_{e}$

The input and output signal in the identification are the current $i$ and rotation velocity $\omega$ of servo motor respectively.

\subsection{Nonlinear Identification of Stribeck Model Parame- ters}

Eq. (1) shows that the Stribeck model is exponential pattern. Thus the linear identification is unavailable, and linearization of the nonlinear model must be performed.

Exponential term in Eq.1 was carried out by Taylor expansion, taking 6 orders as example, and the above formula can be expressed as

$$
F_{f}=\left(a+b v+c v^{2}+d v^{3}+e v^{4}+f v^{5}+g v^{6}\right) \operatorname{sgn}(v)
$$

Where

$$
\begin{aligned}
& a=F_{s}, b=\sigma-\frac{F_{s}-F_{c}}{v_{s}}, c=\frac{F_{s}-F_{c}}{2 v_{s}{ }^{2}}, d=-\frac{F_{s}-F_{c}}{6 v_{s}{ }^{3}}, \\
& e=\frac{F_{s}-F_{c}}{24 v_{s}{ }^{4}}, f=-\frac{F_{s}-F_{c}}{120 v_{s}{ }^{5}} \quad g=\frac{F_{s}-F_{c}}{720 v_{s}{ }^{6}}
\end{aligned}
$$

In Eq.2, Friction $F_{f}$ can be expressed as the liner power function of the speed $v$. When several $F_{f i}$ and $v_{i}$ sequences were obtained by experiments, then suppose

$$
\begin{aligned}
& \mathbf{F}=\left[\begin{array}{llllll}
F_{f 1} & F_{f 2} & \cdots & F_{f i} & \cdots & F_{f N}
\end{array}\right]^{T}, \\
& \boldsymbol{\theta}=\left[\begin{array}{llllll}
a & b & c & d & e f & g
\end{array}\right] \\
& \boldsymbol{\Phi}=\left[\begin{array}{cccc}
\operatorname{sgn}\left(v_{1}\right) & v_{i} \operatorname{sgn}\left(v_{1}\right) & v_{i}^{2} \operatorname{sgn}\left(v_{1}\right) \cdots & v_{i}^{6} \operatorname{sgn}\left(v_{1}\right) \\
\vdots & & & \\
\operatorname{sgn}\left(v_{i}\right) & v_{i} \operatorname{sgn}\left(v_{i}\right) & v_{i}{ }^{2} \operatorname{sgn}\left(v_{1}\right) \cdots & v_{i}{ }^{6} \operatorname{sgn}\left(v_{i}\right) \\
\vdots & & & \\
\operatorname{sgn}\left(v_{N}\right) & v_{N} \operatorname{sgn}\left(v_{N}\right) & v_{i}^{2} \operatorname{sgn}\left(v_{1}\right) \cdots & v_{N}{ }^{6} \operatorname{sgn}\left(v_{N}\right)
\end{array}\right]
\end{aligned}
$$

According to Eq. (5), following express can be obtained

$$
\mathbf{F}=\boldsymbol{\Phi} \boldsymbol{\theta}
$$

The optimal estimation value of coefficient matrix $\boldsymbol{\theta}^{\circ}$ was yielded by least square method for the parameter fitting, and the friction model parameters can be obtained as.

$$
\left\{\begin{array}{l}
F_{s}=a \\
v_{s}=-\frac{c}{3 d} \\
F_{c}=F_{s}-2 c v_{s}{ }^{2} \\
\sigma=b+\frac{F_{s}-F_{c}}{v_{s}}
\end{array}\right.
$$

Friction and speed can be expressed as $T_{f}$ torque $(\mathrm{Nm})$ and $\omega$ rotating speed $(\mathrm{rad} / \mathrm{s})$, and units of the friction model parameters should be adjusted correspondingly as well.

Following Equation can be obtained for a servo motor.

$$
i K_{t}=J_{e} \dot{\omega}+B_{e} \omega+T_{e}
$$

Where, $\mathrm{i}$ is current of the motor, $\mathrm{J}_{\mathrm{e}}$ is the inertia of the moving components and rotating components of the feed mechanism, $B_{e}$ is damp and friction torque is $T_{e}$. When the machine tool working platform fed at a uniform speed and operated with no load, the motor rotated at a uniform speed, and $\dot{\omega}$ was 0 , the above formula was expressed as:

$$
i K_{t}=B_{e} \omega+T_{e}
$$
then

When the damping force was regarded as part of friction,

$$
T_{f}=i K_{t}
$$

Where: $T_{f}$ is the friction torque when the machine tool fed at a uniform speed. The relation between the motor friction torque $T_{f}$ and rotating speed $\mathrm{n}$ can be got on basis of the current $i$ and rotating speed $n$ by the signal collection system, when the machine tool servo axis operated with no load at a uniform speed under various speeds. This relation can be converted into the relationship between the working platform feed speed $\mathrm{v}$ and friction force Ff, and Stribeck curve was then yielded.

\section{DESIGN INPUT SIGNAL FOR PARAMETER IDENTIFICATION}

As for commercial NC system, current i cannot directly be taken as control variable and intput in. Merely programming position signal $\mathrm{u}$ can exert effect on the servo system of NC machine. Hence, the so-called ideal excitation signal cannot be obtained directly. it only can be acquired approximately in an indirect way.

$$
\begin{aligned}
& \text { as } y=K_{b s} \theta \text {, and } \omega=\dot{\theta}, \text { substitute to Eq. (1) } \\
& i=J_{e} \ddot{y} /\left(K_{b s} K_{t}\right)+B_{e} \dot{y} /\left(K_{b s} K_{t}\right)+T_{e} / K_{t}
\end{aligned}
$$

Assume $y$ is the conic of time, there is $y=a t^{2} / 2$, where, a is a constant, substituting a to the formula above,

$$
i=a J_{e} /\left(K_{b s} K_{t}\right)+a t B_{e} /\left(K_{b s} K_{t}\right)+T_{e} / K_{t}
$$

Then given.

$$
k_{1}=a J_{e} /\left(K_{b s} K_{t}\right)+T_{e} / K_{t}, \text { and } k_{2}=a B_{e} /\left(K_{b s} K_{t}\right) \text { are }
$$

When $y$ is the conic of time, current signal refers to the composite of square wave signal and ramp signal. Square wave step signal and ramp signal are the excitation signals usually used in system identification. Here, the acceleration of displacement curve $\mathrm{y}$ is a.

Assume that the required excitation signal $u$ is constituted by $\mathrm{n}$ different accelerating curves. a refers to acceleration of the $\mathrm{i}$ curve, $\mathrm{u}$ denotes the displacement and $\mathrm{v}_{\mathrm{i}}$ represents the velocity, then

$$
u=\left\{\begin{array}{l}
\frac{1}{2} b_{1} t^{2}, 0<t \leq t_{1} \\
\frac{1}{2} b_{1} t_{1}^{2}+\frac{1}{2} b_{2}\left(t-t_{1}\right)^{2}, t_{1}<t \leq t_{2} \\
\ldots \\
\frac{1}{2} b_{1} t_{1}^{2}+\frac{1}{2} b_{2}\left(t_{2}-t_{1}\right)^{2}+\ldots+\frac{1}{2} b_{n-1}\left(t_{n-1}-t_{n-2}\right)^{2} \\
\quad+\frac{1}{2} b_{n}\left(t-t_{n-1}\right)^{2}, t_{n-1}<t \leq t_{n}
\end{array}\right.
$$


In Eq. (8), the position command curve is the conic of time. To realize its G-code programming, the conic is discretized to small straight line segments according to NC interpolation period. Then the small straight line segments are conducted position and feeding velocity programming to generate effective excitation signals. The acceleration command of the excitation signals is assumed as the square wave signals of variable amplitude illustrated as (Fig. 3(a)). And they are transferred to ramp velocity signals by time integral, illustrated as Fig. 3(b). Using time integral again, displacement signal are finally produced, illustrated as (Fig. 3(c)). Corresponding G-code commands are obtained as (Table 1).

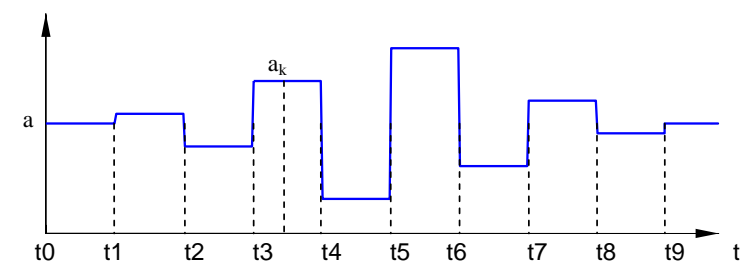

(a) Time-Accelerate Curve

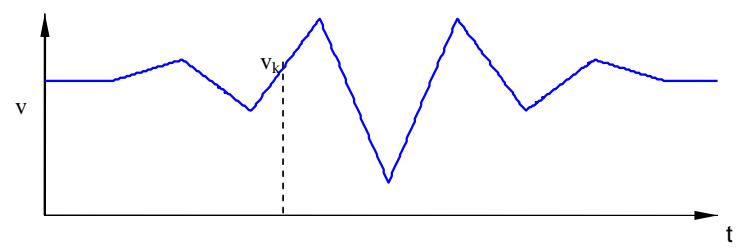

(b) Time-Velocity Curve

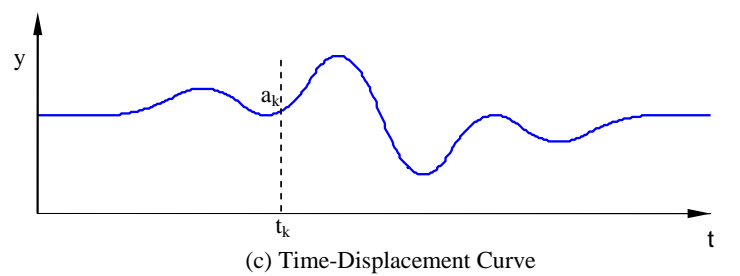

Fig. (3). The generation principle of identifying excitation displacement signal.

Table 1. G-Code of the Generated Conic Displacement Curve

\begin{tabular}{|c|}
\hline G Code \\
\hline \hline $\mathrm{N} 20 \mathrm{~L} 1=0.0001 \mathrm{~L} 2=0.7$ \\
$\mathrm{~N} 30 \mathrm{~L} 12=\mathrm{E} 90001 / 10000+\mathrm{L} 1$ \\
$\mathrm{~N} 40 \mathrm{G} 53$ \\
$\mathrm{~N} 50 \mathrm{G} 90 \mathrm{G} 01 \mathrm{YL} 12 \mathrm{FL} 12$ \\
$\mathrm{~N} 60 \mathrm{G} 91 \mathrm{G} 01 \mathrm{Y} 0.0001 \mathrm{~F} 1.4$ \\
$\mathrm{~N} 103 \mathrm{Y} 0.0002 \mathrm{~F} 2.2$ \\
$\mathrm{~N} 104 \mathrm{Y} 0.0003 \mathrm{~F} 2.9$ \\
$\ldots$ \\
$\mathrm{N} 195 \mathrm{Y} 0.0001 \mathrm{~F} 1.3$ \\
$\mathrm{~N} 228 \mathrm{Y} 0.0004 \mathrm{~F} 4.1$ \\
$\mathrm{~N} 229 \mathrm{Y} 0.0003 \mathrm{~F} 3.4$ \\
$\mathrm{~N} 230 \mathrm{Y} 0.0003 \mathrm{~F} 2.6$ \\
$\mathrm{~N} 231 \mathrm{Y} 0.0002 \mathrm{~F} 1.9$ \\
$\mathrm{~N} 233 \mathrm{M} 02$ \\
\hline
\end{tabular}

\section{IDENTIFICATION EXPERIMENT FOR SERVO SYSTEM}

The identification experiments are performed in the grinding wheel dressing system of a large NC gear grinding machine, as shown in (Fig. 4). Where, diamond roller is installed on $\mathrm{W}$ axis, and high-speed spindle grinding wheel system on $\mathrm{Y}$ axis. Then relative synthesize movement between $\mathrm{Y}$ axis and $\mathrm{W}$ axis can form tract needed. They are installed separately. The NUM 3050 NC system of Schneider Electric Company is applied in the machine. The current $i$ and rotation velocity signal $\omega$ required in identifying $J$ and B can be obtained by the external interface provided by servo driver. In the experiment of equivalent inertia and equivalent damping, the input signal is multiplied by adjusted scale factor $\mathrm{cl}$ to generate excitation signals respectively. Meanwhile, the corresponding system response signals are acquired. One set of input and output signals are illustrated in (Fig. 5). Five different coefficients $\mathrm{c} 1$ are applied in five experiments respectively, the identification results are presented in (Fig. 6). Where, with the gradual increase of coefficient $\mathrm{cl}$, the equivalent rotation inertia and equivalent damping are rapidly convergent after the second experiment and show stable result.

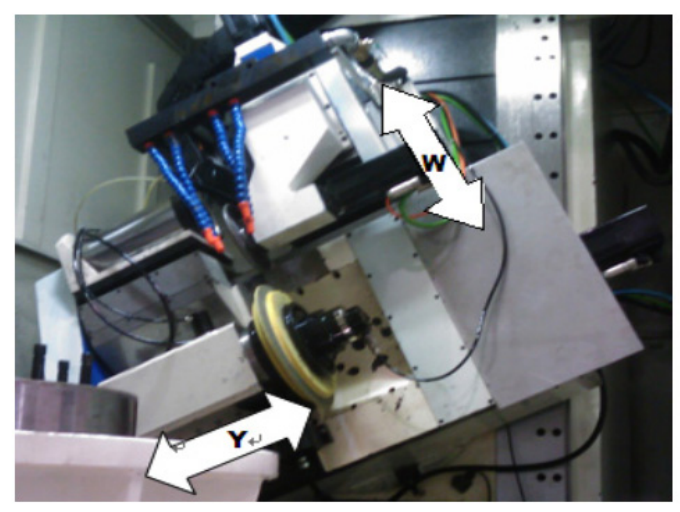

Fig. (4). $\mathrm{Y}$ axis of servo dressing feeding.

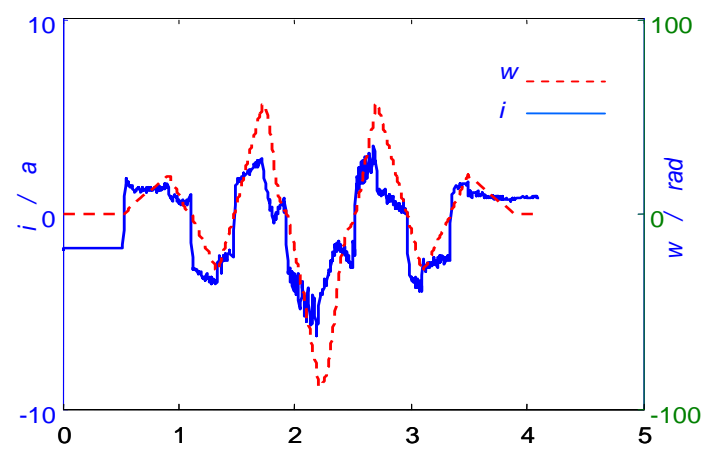

Fig. (5). Input and output signals for identification system of grinding wheel.

Identification experiments of Stribeck model parameters in the servo system also were performed in the CNC gear grinding machine, and friction of moving components on the $\mathrm{Y}$ axis was investigated .The $\mathrm{Y}$ axis servo motor torque constant $\mathrm{K}_{\mathrm{t}}=1.1 \mathrm{~N} / \mathrm{A}$, screw lead $\mathrm{L}=5 \mathrm{~mm}$. In no-load cases, 
various speeds were given on the $\mathrm{Y}$ axis for repeatable feeding at a uniform speed. Current $i$ and feeding speed $F$ were collected from two opposite directions. Due to the same approach, the research adopted the friction in the positive direction for study. The friction torque $T_{\mathrm{f}}$ and angle speed $\omega$ were shown in (Table 2), the discrete points of the angle speed and friction were shown in (Fig. 7).

According Eq.2 and Eq.3, parameters of Stribeck friction model can be got by the least square method as follows:

$\delta: 1, \mathrm{~F}_{\mathrm{s}}: 1.4873 \mathrm{Nm}, \mathrm{F}_{\mathrm{c}}: 1.0723 \mathrm{Nm}, \mathrm{v}_{\mathrm{s}}: 2.6102 \mathrm{rad} / \mathrm{s}, \sigma:$ $0.01985, \mathrm{Nm} / \mathrm{rad} / \mathrm{s}$.

Optimized parameters can be further obtained by manual adjustments as follows:

$\delta: 1, \mathrm{~F}_{\mathrm{s}}: 1.4873 \mathrm{Nm}, \mathrm{F}_{\mathrm{c}}: 1.0080 \mathrm{Nm}, \mathrm{v}_{\mathrm{s}}: 3.6543 \mathrm{rad} / \mathrm{s}, \sigma:$ $0.01707 \mathrm{Nm} / \mathrm{rad} / \mathrm{s}$

The fitting data are illustration as (Fig. 7) (real line).

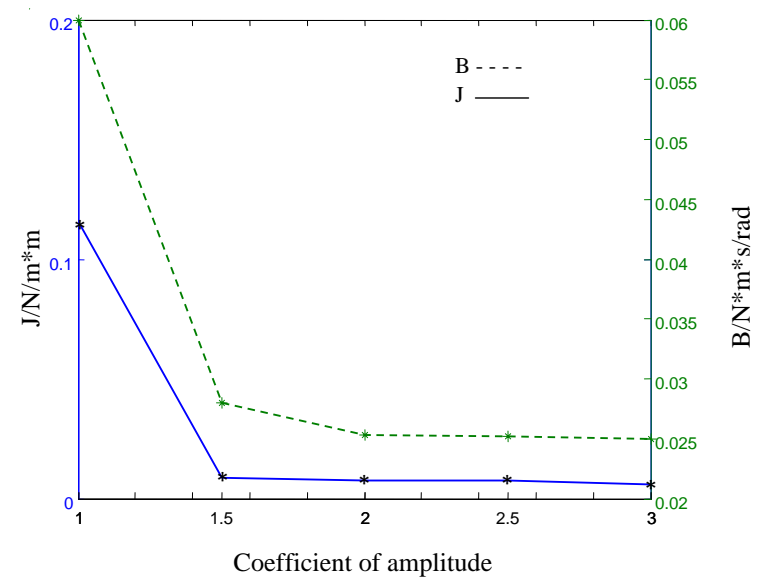

Fig. (6). Result of Identification for inertia and damping.

Table 2. Data of Current and Velocity from Servo System when Forth Feeding

\begin{tabular}{|c|c|c|c|}
\hline$\omega(\mathbf{r a d} / \mathbf{s})$ & $\left.T_{f} \mathbf{N m}\right)$ & $\omega(\mathbf{r a d} / \mathbf{s})$ & $\left.T_{f} \mathbf{N m}\right)$ \\
\hline \hline 0.0209 & 1.5095 & 1.2566 & 1.2275 \\
\hline 0.0419 & 1.2059 & 1.6755 & 1.2414 \\
\hline 0.1047 & 1.2670 & 2.0944 & 1.1936 \\
\hline 0.2094 & 1.4248 & 2.5133 & 1.1606 \\
\hline 0.4189 & 1.2646 & 2.9322 & 1.1485 \\
\hline 0.8378 & 1.2271 & 3.3510 & 1.1286 \\
\hline 3.7699 & 1.1081 & 25.1327 & 1.3040 \\
\hline 4.1887 & 1.1298 & 29.3215 & 1.3676 \\
\hline 8.3775 & 1.0960 & 33.5103 & 1.4400 \\
\hline 12.5663 & 1.1251 & 37.6991 & 1.5050 \\
\hline 16.7551 & 1.1686 & 41.8879 & 1.5504 \\
\hline 20.9440 & 1.2456 & & \\
\hline
\end{tabular}

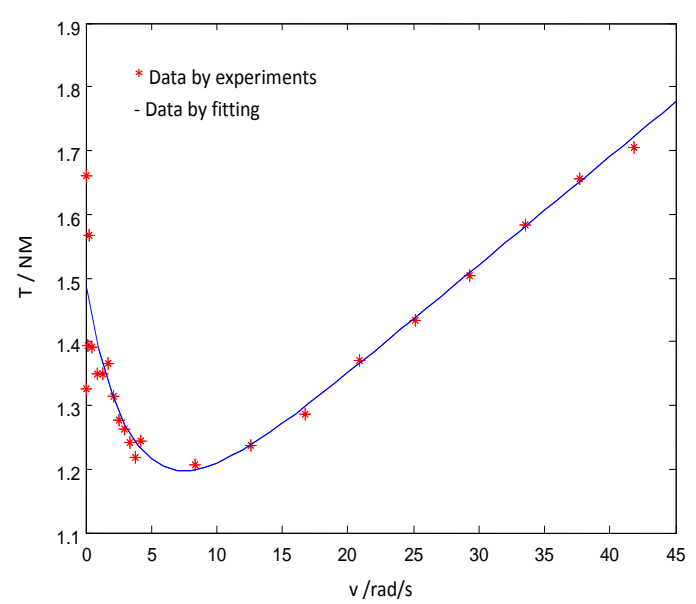

Fig. (7). Stribeck curve by experiments.

\section{CONCLUSIONS}

In this study, simplified control model of NC machine servo system is firstly established. The internal signals of NC system, including current and rotation velocity, are employed as the input and output signals to build the linear ARMA model that can identify the dynamic parameters such as equivalent inertia and equivalent damping. Finally the least squares method is applied to find solution. High order Taylor expansion method was adopted in this research to achieve the linearization for the nonlinear friction exponential model. Parameters of friction model were also finally obtained by the least square method. To verify the effectiveness of the method, identification experiments are conducted on the $\mathrm{Y}$ axis of the feeding system of a large $\mathrm{NC}$ grinding gear machine. And the results indicate that the method is characterized by rapid identification convergence and correct result, and can be applicable for the assessment of the systematical lubrication or assembling performance in engineering applications.

\section{CONFLICT OF INTEREST}

The author(s) confirm that this article content has no conflicts of interest.

\section{ACKNOWLEDGEMENT}

This project was supported by the Natural Science Foundation of Shanghai in China (Grant No. 13ZR1427500), the Key Projects in the National Science \& Technology Pillar Program of China (Grants No. 2012BAF01B02) and the National Natural Science Foundation of China (Grant No 51005158).

\section{REFERENCES}

[1] X.S. Mei, M. Tsutsumi and T. Tao, "Study on the compensation of error by stick-slip for high-precision table", International Journal of Machine Tools \& Manufacture, vol. 44, pp. 503-510, 2004.

[2] Q. Liu, L. Er and L.J. Kun, "Overview of characteristics, modeling and compensation of nonlinear friction in servo systems", Systems Engineering and Electronics, vol. 24, no.11, pp. 45-59, 2002. 
[3] K. Erkorkmaz and Y. Altintas, "High speed CNC system design. Part II: modeling and identification of feed driver", International Journal of Machine Tools \& Manufacture, vol. 41, pp.1487-1509, 2001.

[4] C. Guangsheng. "Research on error synthetic compensation and application in large-scale gear grinding machine", Ph.D. thesis, School of mechanical engineering, Xian Jiaotong University, Xian, China, 2011.
[5] S. Cohn, "Dynamic friction measurement, modeling, and compensation for precise motion control", New Jersey Institute of Technology, New Jersey, 1998.

[6] Y. Zhou, "Investigation on sensorless evaluation for numeric control machine tool driving system", Ph.D. thesis, School of mechanical engineering, Xian Jiaotong University, Xian, China, 2009.

[7] L. Yanjun and Z. Ke, "Theory of system identification and application", Beijing, Defend industrial press, 2003.

Received: August 13, 2013

Revised: August 28, 2013

Accepted: August 28, 2013

(C) Guangsheng and Haolin; Licensee Bentham Open.

This is an open access article licensed under the terms of the Creative Commons Attribution Non-Commercial License (http://creativecommons.org/licenses/by-nc/3.0/) which permits unrestricted, non-commercial use, distribution and reproduction in any medium, provided the work is properly cited. 